Special Issue of the 6th International Congress \& Exhibition (APMAS2016), Maslak, Istanbul, Turkey, June 1-3, 2016

\title{
Spectroscopic Characterization of Titanium Alloy Surface in a Biological Medium
}

\author{
E. Nouicer ${ }^{a, *}$, F.Z. Benlahreche ${ }^{b}$ And A. Nouicer ${ }^{c}$ \\ ${ }^{a}$ Ceramics laboratory, Physics Department, Constantine 1 University, Constantine 25000, Algeria \\ ${ }^{b}$ Engineering of Pharmaceutical Processes Faculty, Constantine 3 University, 25000, Algeria \\ ${ }^{c}$ Electrical Engineering Department, University of Skikda, BP26 Route Elhadaik, Skikda 21000, Algeria \\ This work is aimed to study the effect of a biological medium simulated body fluid on surface modification of \\ titanium alloy Ti6Al4V. Electrochemical techniques and the Raman spectroscopy are used. Polarization curves, \\ plotted at different scan rates $(5,1,0.5$, and $0.2 \mathrm{mV} / \mathrm{s}$ ), show a large range of passivation (above $3000 \mathrm{mV}$ ), with \\ no occurrence of transpassivation. The return sweep shows the negative hysteresis with the shift of the corrosion \\ potential in the more noble direction. The corrosion current is generally very low. These observations clearly \\ confirm the high stability of the $\mathrm{TiO}_{2}$ passive film. The Raman spectroscopy shows that titanium dioxide formed \\ consists of rutile phase. It was found that the scan rate has not a significant effect on the passivation phenomenon. \\ However, it influences the corrosion potential and the current density. Electrochemical impedance spectroscopy \\ allowed to establish the Nyquist diagrams and Bode around the equilibrium potential, and at different imposed \\ potentials in the passivation field. The system behavior is not purely capacitive and so it is necessary to take \\ in consideration the constant phase element. The impedance diagrams at different imposed potentials on the \\ passivation field are composed only of a single loop.
}

DOI: 10.12693/APhysPolA.131.28

PACS/topics: 82.45.Bb, 82.80.Fk

\section{Introduction}

Titanium and its alloys are widely used because of their interesting properties, especially their excellent corrosion resistance due to high chemical inertness, combined with low density compared to steel [1-6]. Applications of titanium alloys in the medical field as implants or prostheses among other uses [7-12] led to define for the purposes of research, simulated biological media to the human body with concentrations equal to that of ions, like blood plasma. The temperature was maintained at $37^{\circ} \mathrm{C}$ and $\mathrm{pH}$ near 7.4.

Given the complexity and the impossibility of any chemical composition of blood plasma or bone, several physiological media are available, which contain the main elements. Both media are often encountered Ringer's and Hank's Leinenbach [13]. Other authors use phosphate buffer solutions (PBS) of relatively variable composition. In fact, there is no real consensus yet on the composition of different physiological synthetic solutions for research purposes (blood plasma, saliva, urine, etc.). In a comparative study, Gurappa et al. [14] studied the electrochemical behavior of the following materials: pure titanium, Ti-6Al-4V, 316L stainless steel and cobalt-based alloy in a deaerated Hank solution at a temperature of $37^{\circ} \mathrm{C}$. Based on polarization techniques and impedance measurements, $\mathrm{Ti}-6 \mathrm{Al}-4 \mathrm{~V}$ alloy presents a low corrosion rate with good film stability. Shukla et al. [15] studied the passive behavior of different materials: pure titanium $\mathrm{CP}$,

*corresponding author; e-mail: n_elamine@yahoo.fr
Ti-6Al-4V and Ti-13.4Al-29Nb in the Hank medium, all alloys were spontaneously passivated during immersion. The results indicate that the potentiodynamic passivation currents have the same magnitude. Electrochemical impedance spectroscopy (EIS) studies indicated an increase of the passive film resistance with the immersion time.

The effect of fluoride ions on the passive behavior of Ti6Al4V alloy in Ringer's solution was studied by Schmidt et al. [16]. The open circuit potential (OCP) shifts to more negative values when fluoride ions are added. The polarization curves exhibit active-passive behavior that changes with the presence of fluoride ions. The results of electrochemical impedance spectroscopy, obtained as a function of immersion time at OCP, show an almost capacitive behavior and a large passivation domain that extends beyond $3.5 \mathrm{~V}$.

\section{Material and experimental techniques}

\subsection{Material}

The Ti6Al4V alloy was provided by CEZUS company (France). Its composition is given in Table I.

TABLE I

Composition of Ti6Al4V alloy [wt.\%]

\begin{tabular}{c|c|c|c|c|c|c|c}
\hline \hline $\mathrm{Al}$ & $\mathrm{V}$ & $\mathrm{C}$ & $\mathrm{N}$ & $\mathrm{H}$ & $\mathrm{O}$ & $\mathrm{Fe}$ & $\mathrm{Ti}$ \\
\hline 6.08 & 4.03 & 0.061 & 0.005 & 0.002 & 0.131 & 0.143 & $\mathrm{bal}$.
\end{tabular}

\subsection{Electrochemical techniques}

Cyclic polarization measurements and impedance were performed in a glass cell with three electrodes: a working 
electrode, a platinum counter electrode and a saturated calomel reference electrode (SCE).

The composition of biological medium (SBF) is given in Table II.

Composition of the SBF medium [17].

TABLE II

\begin{tabular}{c|c|c|c|c}
\hline \hline & $\mathrm{NaCl}$ & $\mathrm{KCl}$ & $\mathrm{CaCl}_{2}$ & $\mathrm{NaHCO}_{3}$ \\
\hline contents $[\mathrm{g} / \mathrm{l}]$ & 9 & 0.43 & 0.24 & 0.2
\end{tabular}

The electrochemical measurements were conducted using a potentiostat type EG \& G Model 283, combined with a frequency response analyzer, Model 1025, controlled by computer. The polarization curves were performed using the software Soft CorrIII, over a wide range of potential $[-0.5 \mathrm{~V}, 3 \mathrm{~V}]$. On the impedance diagrams, we have established using the Power Suite software. The frequency range is between $10^{-2}$ and $10^{5} \mathrm{~Hz}$.

Tests are conducted in open air at a temperature set at $37^{\circ} \mathrm{C}$.

\section{Results and discussion}

\subsection{Open circuit potential measurement}

The evolution of equilibrium potential of the system in open circuit is shown in Fig. 1. The potential increases with time until reaching a more noble value near $-390 \mathrm{mV}$ after one hour. This behavior may be attributed to the formation of a protective oxide film. The Raman spectrum is shown in Fig. 2; the film formed consists mainly of $\mathrm{TiO}_{2}$ in the rutile phase.

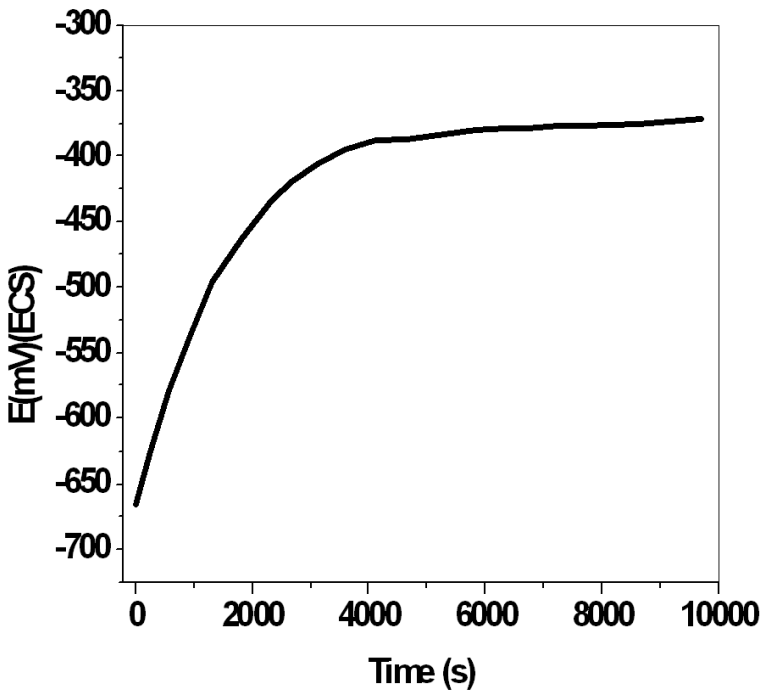

Fig. 1. Evolution of corrosion potential with time of Ti6Al4V alloy in SBF.

\subsection{Cyclic polarization}

In the SBF solution, at a temperature of $37^{\circ} \mathrm{C}$, the cyclic polarization curves plotted on a large range of potential at different scan rates are shown in Fig. 3a,b. At the scan rate of $5 \mathrm{mV} / \mathrm{s}$, the electrochemical behavior is passive. Beyond $3 \mathrm{~V}$, the domain of transpassivation has

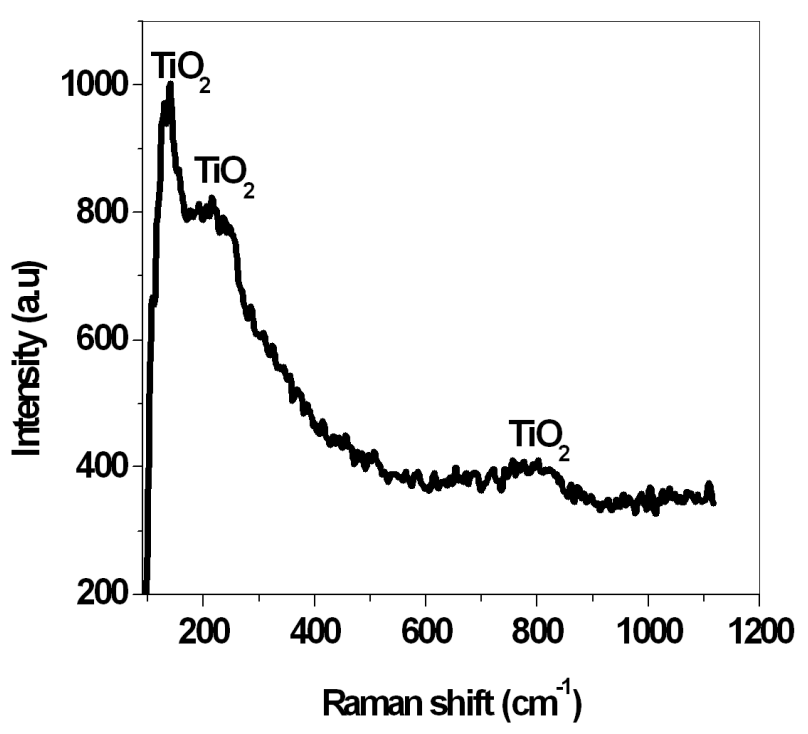

Fig. 2. Raman spectroscopy of the formed $\mathrm{TiO}_{2}$.
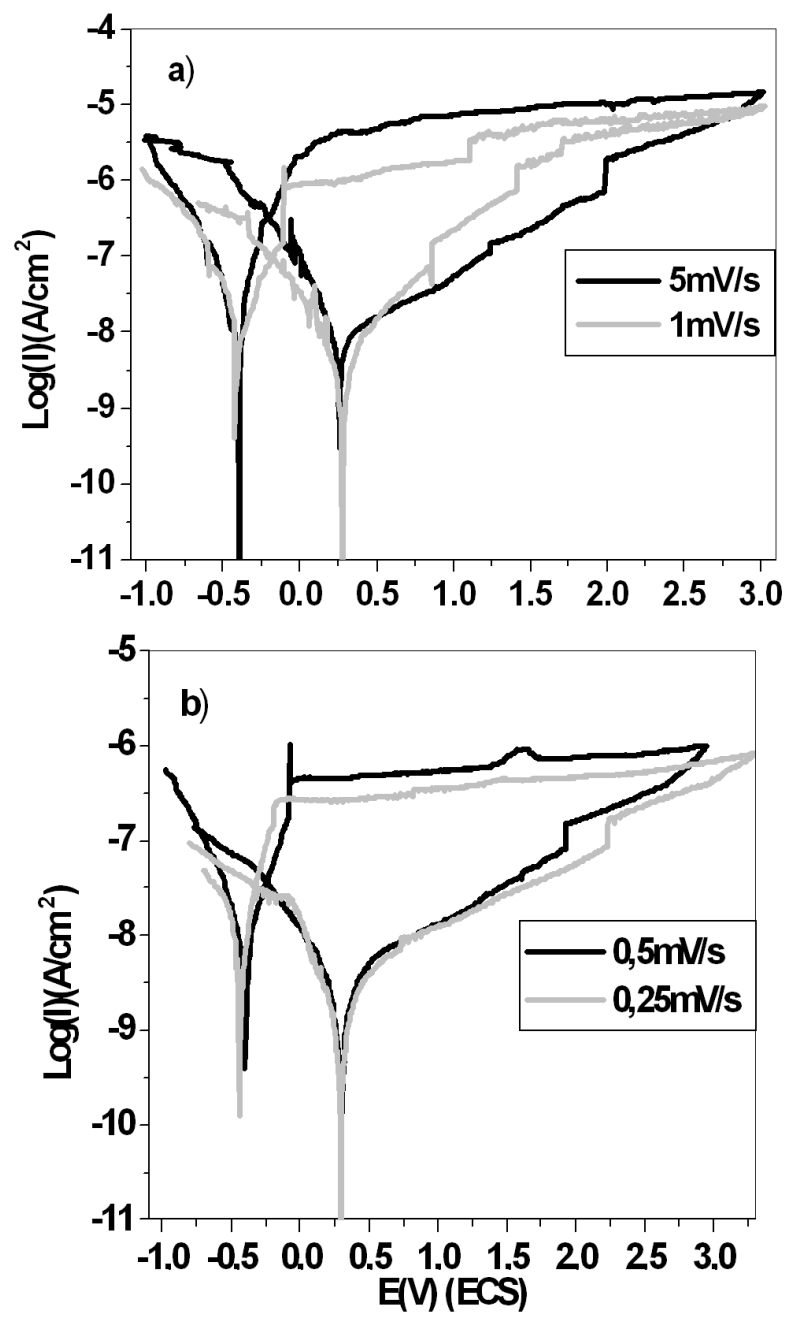

Fig. 3. Cyclic polarization curves (a) at scan rates of 5 and $1 \mathrm{mV} / \mathrm{s}$ and (b) at scan rates of 0.5 and $0.25 \mathrm{mV} / \mathrm{s}$. 
not been reached, the corrosion potential is the order of $-392 \mathrm{mV}$ and the current density is equal to $39 \mathrm{nA} / \mathrm{cm}^{2}$. At a scan rate of $1 \mathrm{mV} / \mathrm{s}$, the behavior is always passive, the corrosion potential is about $-398 \mathrm{mV}$ and the current density of $32 \mathrm{nA} / \mathrm{cm}^{2}$. For low scan of 0.5 and $0.25 \mathrm{mV} / \mathrm{s}$, the corrosion potentials are respectively $-400,-420 \mathrm{mV}$ and the corrosion current densities are of the same order of magnitude ( 28 and $27 \mathrm{nA} / \mathrm{cm}^{2}$ ), there is a gradual decrease of the passivation currents densities, different cyclic polarization results are summarized in Table III.

TABLE III

Corrosion potential $[\mathrm{mV} / \mathrm{SCE}]$ and current $\left[\mathrm{nA} / \mathrm{cm}^{2}\right]$ of cyclic polarization at various scan rates $[\mathrm{mV} / \mathrm{s}]$.

\begin{tabular}{c|c|c|c|c}
\hline \hline \multirow{2}{*}{$\begin{array}{c}\text { Scan } \\
\text { rate }\end{array}$} & \multicolumn{2}{|c|}{ Forward scan } & \multicolumn{2}{c}{ Reverse scan } \\
\cline { 2 - 5 } & potential & current & potential & current \\
\hline 5 & -392 & 39 & 253 & 6.85 \\
1 & -398 & 32 & 267 & 1.99 \\
0.5 & -400 & 28 & 296 & 1.22 \\
0.25 & -420 & 27 & 297 & 0.954
\end{tabular}

\subsection{Electrochemical impedance spectroscopy analysis}

In order to understand the polarization effect on the film formation, the Nyquist and Bode diagrams were first plotted near the equilibrium potential, then for the chosen potentials in the passivation region which corresponds to a very low anodic current. As shown in Fig. 4, the system behavior is not purely capacitive and so it is necessary to take into consideration the constant phase element Z (CPE).

The impedance diagrams plotted in the Nyquist plane (Fig. 4) show a capacitive loop with a single time constant for all imposed potential, indicating a single compact layer. The equivalent electrical circuit of the $\mathrm{Ti} 6 \mathrm{Al} 4 \mathrm{~V} / \mathrm{SBF}$ interface is similar to a resistance $R_{e}$

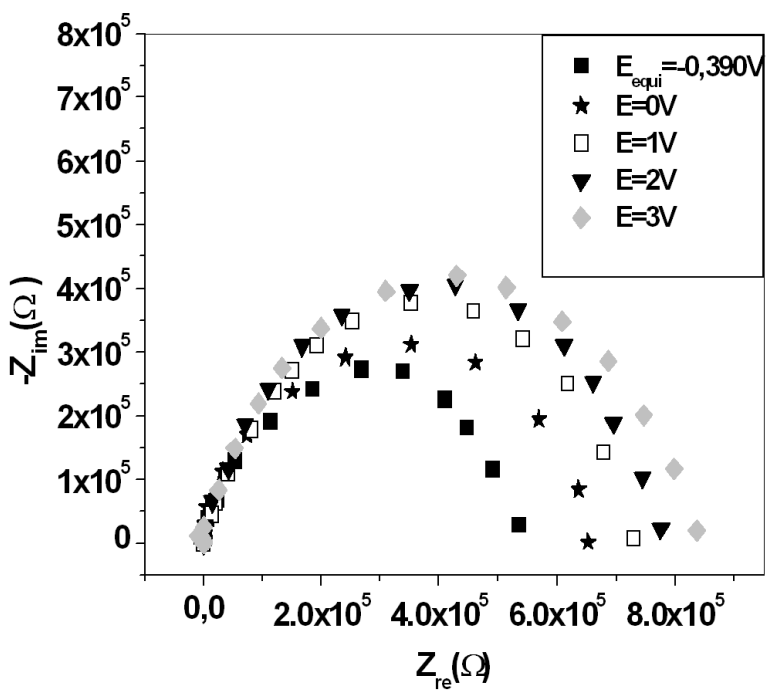

Fig. 4. Nyquist diagram at different imposed potentials.

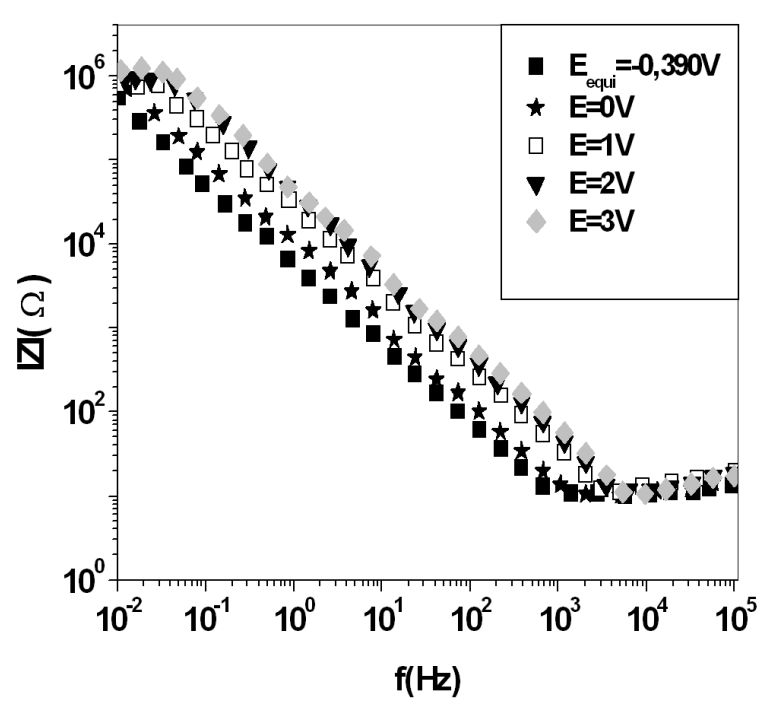

Fig. 5. Bode diagram at different imposed potentials.

of the electrolyte in series with the constant phase element $(\mathrm{CPE})$, which is in parallel with the corrosion resistance $R_{t}$.

From Fig. 4, the change in potential from $E_{e q}$ to $3000 \mathrm{mV}$ caused an increase in $R_{t}$. The larger the capacitive loop, the higher the corrosion resistance.

Bode plots (log|impedance| versus $\log \mid$ frequency $\mid$ ) at various potentials are represented in Fig. 5 . These plots have a linear pattern at middle frequencies with $n$ values of 0.92 and 0.97 at $E_{e q}$ and at $3000 \mathrm{mV}$, respectively. The increasing trend in $n$ to values close to 1 corresponding to the purely capacitive behavior is related to the growth of the passive and compact oxide film. At equilibrium, its thickness is estimated as $5 \mathrm{~nm}$ and reaches about $44 \mathrm{~nm}$ in the imposed potential of $3 \mathrm{~V}$.

TABLE IV

Electrical parameters of the equivalent circuit obtained by fitting the experimental results of EIS.

\begin{tabular}{c|c|c|c|c|c}
\hline \hline $\begin{array}{c}\mathrm{E}_{\text {quil }} \\
{[\mathrm{V}]}\end{array}$ & $\begin{array}{c}C \\
{\left[\mu \Omega^{-1} \mathrm{~s}^{n} \mathrm{~cm}^{-2}\right]}\end{array}$ & $\begin{array}{c}R_{s} \\
{[\Omega]}\end{array}$ & $\begin{array}{c}R_{t} \\
{[\mathrm{M} \Omega]}\end{array}$ & $n$ & $\begin{array}{c}\text { film } \\
{[\mathrm{nm}]}\end{array}$ \\
\hline-0.390 & 32.9 & 14.83 & 0.5713 & 0.92 & 5 \\
0 & 19.9 & 15.5 & 0.7012 & 0.93 & 8 \\
1 & 7.7 & 15.9 & 0.8107 & 0.95 & 20 \\
2 & 4.2 & 16.65 & 0.9373 & 0.96 & 36 \\
3 & 3.5 & 16.7 & 1.2422 & 0.97 & 44
\end{tabular}

The values of impedance parameters are given in Table IV, results indicate that the resistance values, film thickness, and exponent $n$ gradually increase with the increase in potential, whereas the capacitance decreases.

\section{Conclusion}

In this work, polarization curves, plotted at different scan rates, in the biological medium $(\mathrm{SBF})$, show a large field of passivation (above $3000 \mathrm{mV}$ ), with no occurrence 
of transpassivation, breakdown potential has not been reached. Return sweep shows very low corrosion current. These observations clearly confirm the high stability of the passive film, due to a protective layer existing in a wide potential range. Note that the scan rate has a significant influence on the passivation current. However, it influences the corrosion potential and the passivation current.

Electrochemical impedance spectroscopy allowed to establish the Nyquist and Bode diagrams around the equilibrium potential, and then at imposed potentials in the field of passivation. It was found that the system behavior is not purely capacitive and it is necessary to take into account the constant phase element CPE.

Impedance parameters, derived from the Bode diagram and Nyquist, show that with increase of the applied potential, taken on the level of passivation, the charge transfer resistance, the exponent $n$ also grows, while the capacitance decreases, meaning that one approaches the purely capacitive behavior, which is attributed to the growth of a passive oxide film and compact. The results of cyclic polarization and EIS analyses are in good agreement with the literature results and specially the passivable behavior of Ti6Al4V alloy.

\section{References}

[1] R.W.-Wei Hsu, C.C. Yang, C.A. Huang, Y.S. Chen, Mater. Sci. Eng. A 380, 100 (2004).

[2] Z. Cai, T. Shafer, I. Watanabe, M.E. Nunn, T. Okabe, Biomaterials 24, 213 (2003).
[3] S.G. Lakshmi, S. Tamilselvi, N. Rajendran, M.A.K. Babi, D. Arivuoli, Surf. Coat. Technol. 182, 287 (2004).

[4] C.-E.B. Marino, L.-H. Mascaro, J. Electroanalyt. Chem. 568, 115 (2004).

[5] I. Gurrappa, D.-V. Reddy, J. Alloys Comp. 390, 270 (2005).

[6] L.C. Tsao, Acta Phys. Pol. A 122, 561 (2012).

[7] Y. Xie, X. Liu, P.-K. Chu, X. Zheng, C. Ding, Surf. Coat. Technol. 200, 1950 (2005).

[8] B.-S. Ng, I. Annergren, A.-M. Soutar, K.-A. Khor, A.-E.W. Jarfors, Biomaterials 26, 1087 (2005).

[9] C. Jaeggi, P. Kern, J. Michler, T. Zehnder, H. Siegenthaler, Surf. Coat. Technol. 200, 1913 (2005).

[10] K. Azumi, N. Yasui, M. Seo, Corros. Sci. 42, 885 (2000).

[11] J.-P. Gueneau de Mussy, J.-V. Macpherson, J.-L. Delplancke, Electrochim. Acta 48, 1131 (2003).

[12] W. Zhang, C. Wang, W. Liu, Wear 260, 379 (2006).

[13] C. Leinenbach, C. Fleck, D. Eifler, Int. J. Fatigue 26, 857 (2004).

[14] I. Gurappa, Mater. Character. 49, 73 (2002).

[15] A.-K. Shukla, R. Balasubramaniam, S. Bhargava, Intermetallics 13, 631 (2005).

[16] A.M. Schmidt, D.S. Azambuja, Mater. Res. 6, 227 (2003).

[17] L. Thair, U. Kamachi Mudali, S. Rajagopalan, R. Asokamani, Baldev Raj, Corros. Sci. 45, 1951 (2003). 